\section{Management of obstructive urolithiasis in dairy calves with intact bladder and urethra by Fazili's minimally invasive tube cystotomy technique}

\author{
Mujeeb ur Rehman Fazili,1 \\ Hiranya Kumar Bhattacharyya,1 \\ Bashir Ahmad Buchoo, 1 \\ Hamid Ullah Malik, ${ }^{2}$ Shahid Hussain Dar ${ }^{1}$ \\ 1Teaching Veterinary Clinical Complex, \\ 2Division of Clinical Veterinary Medicine, \\ Faculty of Veterinary Sciences and A.H., \\ Shere Kashmir University of Agricultural \\ Sciences and Technology of Kashmir, \\ Shuhama, Srinagar, Jammu and Kashmir, \\ India
}

\section{Abstract}

The present study was planned to evaluate minimally invasive tube cystotomy technique in calves suffering from obstructive urolithiasis having intact urinary bladder and urethra. Fifteen male non-castrated calves with age ranging from 1-10 months (mean 4.05 months), presented for treatment within one to three days (mean 2.2 days) of complete urinary tract obstruction due to urethral calculi with intact bladder and urethra, were included in this study. Under light sedation and local infiltration anaesthesia, all the animals were subjected through left paralumbar fossa, to a minimally invasive surgical tube cystotomy in which catheter was placed in the bladder lumen through a metallic cannula and fixed to the skin with a stay suture (Fazili's technique). All the animals were discharged the same day. Time taken for the procedure varied from 8 to 17 minutes (mean 11.0 minutes). Normal urination resumed in twelve $(80.0 \%)$ calves. Mean time taken for normal urination was 10.50 days. In two of the remaining calves, urine flow stopped through the catheter prematurely and they were then subjected to standard surgical tube cystotomy. One more calf did not urinate normally for 30 postoperative days and was lost to the follow up thereafter. Recurrence of the obstruction was not detected in ten and nine animals observed up to six and 12 months respectively. In conclusion, the outcome of this minimally invasive technique is similar to the standard tube cystectomy. Additionally, the procedure is cost effective, quick, simple and field applicable. It also minimizes exposure of abdominal cavity of metabolically compromised animals. However, the technique needs to be tried in larger number of such calves wherein better quality catheter of larger diameter be used before recommending its extensive use.

\section{Introduction}

Medical treatment of obstructive urolithiasis in ruminants has generally been unrewarding. Some form of surgical intervention is necessary to relieve the obstruction, either by direct removal of the urolith, or by bypassing the obstruction. ${ }^{1}$ Currently the most successful method of treating obstructive urolithiasis both in cattle and small ruminants is surgical tube cystotomy.2-6 It diverts urine through a catheter placed from the urinary bladder exiting through the body wall. The catheter is then intermittently occluded to encourage urination through the urethra. The principal advantages of this technique include a fairly simple procedure, a relatively short duration of anaesthesia, and restoration of full urethral patency in successful cases. ${ }^{7}$ Disadvantages for tube cystotomy include increased hospitalization and intensity of case management. ${ }^{8}$ Cost being a major drawback of surgical tube cystotomy is always a factor in the treatment of ruminants. 1,9 To reduce the costs associated with the tube cystotomy procedure, a percutaneous technique under ultrasound guidance has been developed for placement of the cystotomy tube in goats. ${ }^{10}$ However, this technique was successful in the initial description, but subsequent reports indicate that it is $\mathbf{5 . 6}$ times more likely to require a second procedure to replace the tube following premature tube loss. ${ }^{5}$ The use of minimal invasive surgery decreases the size of the laparotomy incision needed and obviates the need for extensive manual traction on the bladder. ${ }^{11}$ The success of a quick, field-applicable, cheap, minimally invasive tube cystotomy technique for treating obstructive urolithiasis in small ruminants with intact bladder has recently been reported. ${ }^{12}$ The present study was planned to evaluate the technique in calves suffering from obstructive urolithiasis having intact urinary bladder and urethra. The complications encountered and the long term outcome was also determined.

\section{Materials and Methods}

\section{Inclusion criteria}

Fifteen male non-castrated calves presented for complete urinary tract obstruction with intact bladder and urethra were included in this study. Preoperative physical examination findings, historical data, hematology and biochemical results, intra-operative findings and the postoperative outcome and complications were recorded. The animals were re-examined
Correspondence: Mujeeb ur Rehman Fazili, H.No: 78, Lane No.6, Green Park, H.I.G Colony, Bemina, Srinagar, Kashmir, 91-190018 India.

Tel. +91.9419095830 .

E-mail: fazili_mr@yahoo.co.in

Key words: tube cystotomy, obstructive urolithiasis, calves, urinary bladder, urethra.

Contributions: MRF, conceived the idea, performed all the surgeries and prepared the manuscript; HKB, photography, hematobiochemical estimations and tabulation of the generated data; $\mathrm{BAB}$, critically evaluated the manuscript; HUM, designed the stainless steel cannula, conducted hematobiochemical estimations of the latest cases and reviewed the manuscript; SHD, assisted in photography.

Conflict of interests: the authors report no potential conflict of interests.

Received for publication: 25 September 2011. Revision received: 12 April 2012.

Accepted for publication: 1 May 2012.

This work is licensed under a Creative Commons Attribution NonCommercial 3.0 License (CC BYNC 3.0).

(C) Copyright M. Fazili et al., 2012

Licensee PAGEPress srl, Italy

Veterinary Science Development 2012; 2:e11

doi:10.4081/vsd.2012.e11

at the time of catheter removal after resuming normal urination. Follow up was obtained via telephone from owner's every month throughout the first year after surgery.

\section{Surgical procedure}

All the animals were administered sedative diazepam $(0.1 \mathrm{mg} / \mathrm{kg})$ and antibiotic ceftriaxone $(10 \mathrm{mg} / \mathrm{kg})$ intravenously (I.V) preoperatively. Patients were then restrained in standing position and left paralumbar area clipped and prepared for aseptic surgery. Local anaesthesia was achieved by line infiltration using 2 $\mathrm{mL}$ of lignocaine hydrochloride $(2 \%)$ in vertical direction in the mid flank area. Minimally invasive tube cystotomy as previously described wherein the catheter was placed in the bladder lumen through a metallic cannula guided by a finger (passed along with it) via a stab incision in the abdominal wall and then fixed to the skin with a stay suture using braided silk (No.1) in horizontal mattress pattern was followed in all the cases (Figure 1). ${ }^{12}$

The diameter of the metallic cannula and the catheter and its fenestration area were all similar to that used in small ruminants. ${ }^{12}$ The length of the catheter was also decided preoperatively in each case after external assessment of the approximate distance from the 
neck of the empty urinary bladder to the incision site and allowing $7.5 \mathrm{~cm}$ to $10.0 \mathrm{~cm}$ extra to keep urine away from the skin surface (Figure 2).

Time taken from start of the incision to completion of the stay suture fixing the catheter to the skin was recorded. All animals were discharged the same day after advocating owners various dietary modifications including reduction or elimination of wheat bran feeding, provision of grass hay and clean lukewarm water during winter months, addition of table salt ( 10 to $15 \mathrm{~g}$ daily) to ration or to drinking water in these animals.

\section{Postoperative treatment}

Meloxicam $(0.2 \mathrm{mg} / \mathrm{kg})$ and ceftriaxone (10 $\mathrm{mg} / \mathrm{kg}$ ) were administered intramuscularly (I.M), once daily for 3 and 5 days respectively. Immediately following catheterization, fluid $(0.9 \%, \mathrm{NaCl})$ at $15 \mathrm{~mL} / \mathrm{kg}$ was given intravenously to five calves (showing complete anorexia and clinical dehydration). Antiseptic dressing of the incision site using $5 \%$ povidone iodine followed by application of fly repellent ointment three times daily was continued up to $5^{\text {th }}$ day following catheter removal. Ammonium chloride $(200 \mathrm{mg} / \mathrm{kg}$ ) per os was prescribed daily for a period of one month. The catheter was allowed to drain freely for four days (or until normal urination resumed) after which it was occluded on every alternate day with infusion set flow regulating clamp to determine the urethral patency. If the animal was uncomfortable (kicking at belly, repeatedly getting up and down, posturing to urinate, looking at abdomen) after occlusion, the clamp was removed to allow the catheter to drain the bladder. With the catheter occluded, when the animal urinated normally for $48 \mathrm{hr}$, the catheter was then pulled out after release and removal of the cutaneous stay suture. Postoperative management was performed by local field veterinarians at the owner's premises. All the animals were presented again to our hospital for removal of the catheter subsequent to their normal urination. The calves wherein the flow through the catheter stopped before resumption of normal urination were also presented for further treatment.

\section{Results}

All the calves suffering from obstructive urolithiasis included in this study were intact males. They were presented with the complaint of complete absence of urination for one $(3 / 15,20.00 \%)$, two $(5 / 15,33.33 \%)$ and three $(7 / 15,46.67 \%)$ days respectively. The mean duration of clinical signs before presentation was 2.2 days.

Crossbred Jersey calves were mainly
$(10 / 15,66.67 \%)$ involved. Crossbred Holstein Frisian $(3 / 15,20 \%)$ and local/ non-descript $(2 / 15,13.33 \%)$ cases were comparatively less in number.

The age of the calves ranged from 1-10 months (mean 4.05 months). Most of the cases $(13 / 15,86.67 \%)$ were less than six months old. Highest and equal prevalence (together comprising of more than half of the total cases) was recorded in calves aged three $(5 / 15$, $33.33 \%)$ and four $(5 / 15,33.33 \%)$ months.

On clinical examination five calves exhibited tachycardia (mean 91 bpm, range 69-103 bpm) and polypnoea (mean 24 breaths/min, range 15-30 breaths/min). In all the animals, rectal temperature (mean $101.2^{\circ} \mathrm{F}$, range $101.0-102.4^{\circ} \mathrm{F}$ ) was in normal range..$^{13}$

The most frequently observed symptoms included partial or complete anorexia, restlessness, getting up and lying down, striking of the abdomen with hind legs and raised tail. Abdominal distention, grating of the teeth and stretching of the body was noticed less frequently (Figure 3).

White concretions appearing as beaded pearls on the prepucial hair were noticed in nine animals (Figures 4 and 5).

Mild to moderate dehydration was indicated by skin fold test and hematological evaluation in five calves. Deep palpation with both hands on either side of the flank region revealed distended urinary bladder in twelve calves. In the remaining three animals the abdominal musculature was tense on palpation. Prominent urethral pulsation in the ischial region was felt especially when prepucial area was simultaneously rubbed to induce efforts for urination in most (thirteen) of the calves.

In five calves, haemoglobin $(\mathrm{Hb})$ and packed cell volume (PCV) values were elevated (mean $>14.0 \mathrm{~g} / \mathrm{dL}$ and $>54 \%$ respectively) but within normal range. Total leukocyte count (TLC) val- ues (mean $6.13 \times 10^{3} / \mathrm{cmm}$, range 5.65 $11.75 \times 10^{3} / \mathrm{cmm}$ ) were also within normal range. 13

Total serum protein (TSP) values ranged between 5.60 to $7.55 \mathrm{~g} / \mathrm{dL}$ (mean $7.02 \mathrm{~g} / \mathrm{dL}$ ) and that of albumen from 2.0 to $3.2 \mathrm{~g} / \mathrm{dL}$. All these values were also within normal range. 13 Serum creatinine $(>2.7 \mathrm{mg} / \mathrm{dL})$ and urea nitrogen $(>27 \mathrm{mg} / \mathrm{dL}$ ) values were elevated in all the animals.

The sedation and analgesia of the surgical site in all the animals was satisfactory. All the animals except one kept standing throughout the surgery.

The urinary bladder catheterization and application of the stay suture was accomplished without difficulty in all the cases.

Details of the out come of the surgery are presented in Table 1.

Time taken for the procedure varied from 8 to 17 minutes (mean 11.0 minutes).

In all the calves' signs of distress and acute pain subsided immediately after the surgery and normal feeding resumed within four to six hours. The incision site healed uneventfully.

In two calves, flow through the catheter stopped on day third postoperatively. In both of

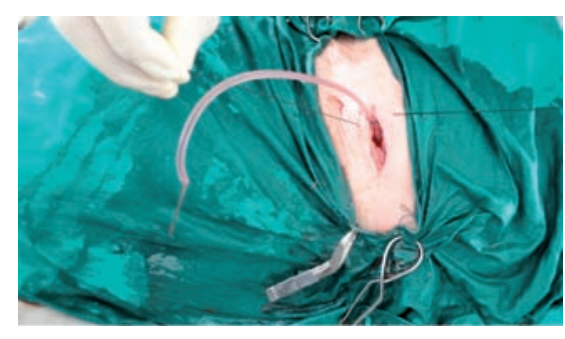

Figure 1. Application of stay suture to the catheter passed into the urinary bladder.

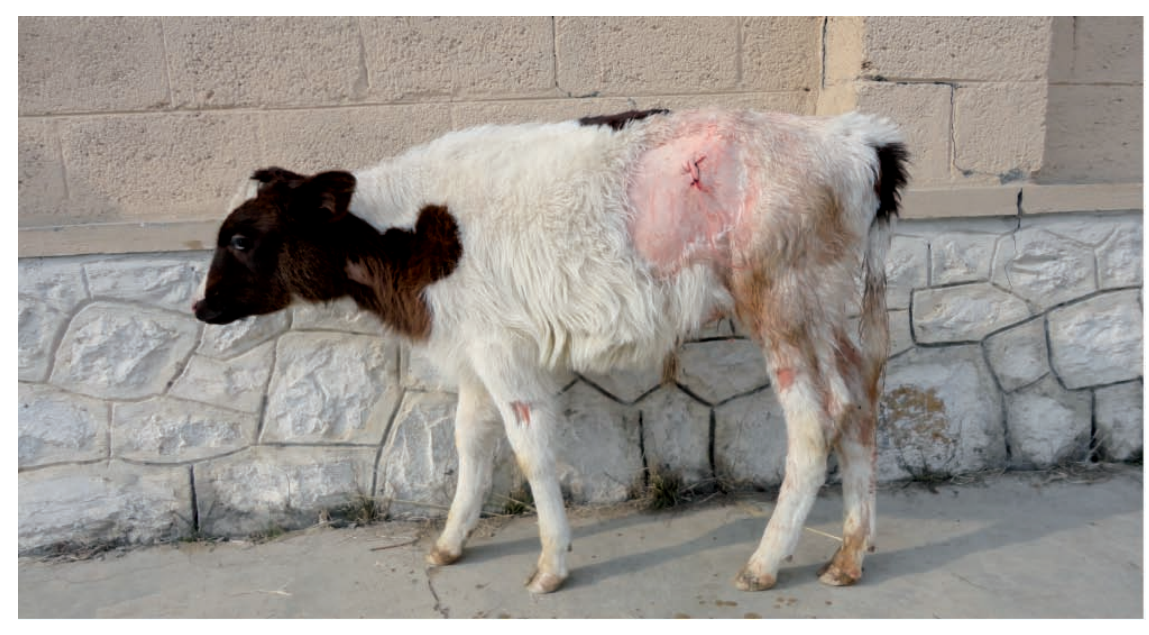

Figure 2. Calf immediately after undergoing Fazili's minimally invasive tube cystotomy. 
them the continuous flow of urine resumed by retrograde flushing of the catheter with normal saline. One of these calves continued to urinate through the catheter till recovery. However, in another calf block in the flow of urine recurred 24 hours after first flushing of the catheter. Third calf was presented on day fifth postoperatively with the same complaint along with abdominal distention and anorexia. In this calf seepage of urine was also detected around the catheter at the incision site. Both of these calves were then subjected to standard tube cystotomy. During laparotomy in both of them, the catheter was found well placed inside the bladder lumen. In the first calf whole of the fenestrated length of the tubing was packed with white concretions and urine was leaking around the catheter through the puncture site of the bladder. The catheter tubing in the other calf had collapsed for a length of four inches inside the urinary bladder. These two cases were then excluded from the study. One more calf that did not resume normal urination up to $30^{\text {th }}$ day after surgery was lost to the follow up.

Normal urination resumed in twelve (80.0\%) calves. Dribbling of the urine in these calves started from day 3 to day 21 postoperatively. Mean time taken for normal urination was 10.5 days.

Ten and nine of the twelve cases with positive outcome did not show recurrence during six and twelve months (respectively) of observation period. Two of the remaining three calves were lost to follow up three and five months following surgery and the other one died seven months postoperatively with some disease unrelated to urinary tract obstruction.

\section{Discussion}

Obstructive urolithiasis remains a longstanding problem in castrated male calves and can cause considerable economic loss due to mortality and treatment costs to the farmer. ${ }^{14-17}$
All the animals included in this study were intact male calves. This finding is in accordance with several earlier reports. $2,18,19$

Crossbred Jersey calves were over-represented in our study. Similar breed distribution has been reported earlier from this region.2,19 Among the various exotic dairy breeds, Jersey has well adapted itself to the agro-climatic conditions of Kashmir valley. However, according to one report, 15 when maintained under comparable conditions, no breed of cattle among those of European origin seems more prone than any other to the formation of calculi.

Majority of the calves in our study were less than six months old. Calves of similar age were reported earlier.2,18,20,21 This finding is in contrast to those reports indicating that the phenomenon is most common in steers and bulls. 6,16

All the clinical signs including tachycardia (in five animals) observed in the calves included in our study are characteristic of abdominal pain arising from distension of urinary bladder following obstruction of urethra. ${ }^{6}$

The intact bladder was diagnosed without difficulty by simultaneous bilateral palpation of distended bladder in the flank region, ure- thral pulsation in the ischeal region and absence of fluid thrill on abdominal ballottement. ${ }^{2}$ Calves suffering from obstructive urolithiasis with intact urinary bladder were presented within three days (mean 2.2 days) of development of the symptoms. Similar duration of clinical signs was reported for small ruminants. ${ }^{4,12}$ In practice more than half of the calves are generally presented with intact bladder. $2,21,22$

Increase in $\mathrm{Hb}, \mathrm{PCV}$ and TSP values in five calves indicated mild dehydration. ${ }^{14}$ On preoperative clinical examination, in these cases dehydration was also indicated by skin fold test. With intent to reduce cost of treatment, fluid therapy was restricted to those showing complete anorexia and/or moderate dehydration only.

Elevated blood urea nitrogen (BUN) and creatinine values noticed in the animals of this study indicate retention of urine. Several workers have reported increase in BUN and creatinine values in cases of obstructive urolithiasis. ${ }^{20,23-25}$

Light sedation using lower doses of diazepam along with local anaesthetic infiltration resulted in satisfactory analgesia and

Table 1. Outcome of Fazili's minimally invasive tube cystotomy technique for obstructive urolithiasis in calves with intact urinary bladder and urethra.

\begin{tabular}{lcc}
\hline Total number of calves treated (n) & 15 \\
Time taken for surgery (minutes) & & $8-17$ (mean 11.0) \\
\hline Number of successful cases (n) & $12(80.0 \%)$ \\
Time taken for normal urination (days) & $3-21$ (mean 10.5) \\
\hline Postoperative observation period: & 3 months & No. of calves: \\
& 6 months & 12 \\
& 9 months & 10 \\
& 12 months & 9 \\
Number of Unsuccessful cases (n) & & $3(20.0 \%)$ \\
Causes of failure: & & 1 \\
Non-resumption of normal urination up to 30 days & 1 \\
Catheter inside urinary bladder: & a) collapsed & 1 \\
\hline
\end{tabular}

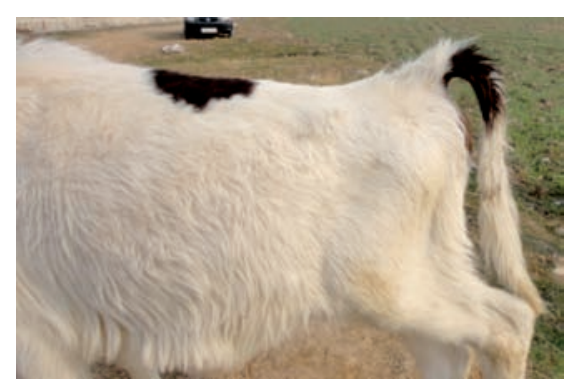

Figure 3. Raised tail and stretching of the body in a calf with obstructive urolithiasis.

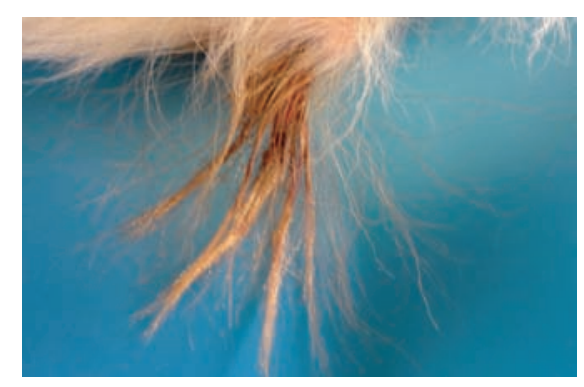

Figure 4. Prepucial hair studded with white concretions in a calf with obstructive urolithiasis.

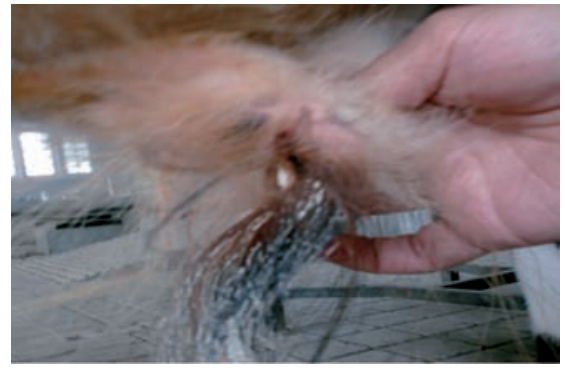

Figure 5. Prepucial hair studded with white concretions appearing as beaded pearls in a calf with obstructive urolithiasis. 
minimal movements of the standing animal during surgery. Surgical intervention while animal kept standing was considered preferable to avoid bladder rupture during lateral recumbency. In one study, more than $50 \%$ of animals undergoing marsupialization for treating obstructive urolithiasis were sedated with xylazine. ${ }^{20}$ However, alpha-2 agonistic sedative induces a large increase in diuresis which could be dangerous in cases of urethral obstruction with intact bladder. ${ }^{22}$

The minimally invasive tube cystotomy technique using a stainless steel cannula to pass a polyvinyl chloride catheter in to the urinary bladder followed by fixation of the catheter to the skin with a stay suture in such small ruminants was accomplished without difficulty in all the cases of this study. 12 The mean time taken to complete the procedure was also similar to that of small ruminants. Surgeon's finger placed over the sharp end of the cannula during catheterization protected the abdominal viscera from damage.

Retrograde flushing of the blocked catheter resulted in resumption of the flow of urine. However, occlusion of the fenestrated portion of the catheter with concretions in one calf and collapse of the catheter inside the urinary bladder in another, made standard tube cystotomy necessary in these animals subsequently. The use of a better quality catheter that would not collapse at body temperature and of wider diameter $(>0.4 \mathrm{~cm})$ that may not get blocked with concretions unlike infusion set tubing used in this study is therefore recommended.

In both the calves that were subsequently subjected to conventional tube cystotomy, the catheter ends were found well placed inside the bladder lumen. Sufficient length of the catheter inside the bladder and a stay suture at the cutaneous level to prevent catheter displacement are the most important advantages of this technique. Displacement of the catheter in the percutaneous approach under ultrasound guidance in small ruminants has been pointed out as the main disadvantage of that technique. ${ }^{5}$

The minimally invasive tube cystotomy technique followed in this study was successful in $80.0 \%(12 / 15)$ of the calves with re-establishment of urine flow in 10.5 days. Recurrence of obstructive urolithiasis was not noticed in successful cases during the postoperative observation period of six (ten animals) and twelve (nine animals) months respectively. Generally a surgical procedure has been considered successful when obstruction did not recur. ${ }^{5}$ The success rate of standard tube cystotomy procedure in ruminants as $76 \%$ to $90 \%$ in the short term, and $86 \%$ in the long term has been reported.2,4,6,12 The mean time taken for reestablishing urine flow in the animals of those studies ranged from seven to 11.5 days. Our results also indicate that animals survive for long periods of time after this minimally inva- sive tube cystotomy in calves suffering from obstructive urolithiasis without recurrence of urinary obstruction as has been reported for standard tube cystotomy in small ruminants. 4 Prevention of recurrent obstructions was addressed by dietary changes and the use of urinary acidifiers. $1,4,6,20$

\section{Conclusions}

In summary, our results indicate that the efficacy of Fazili's technique for treatment of obstructive urolithiasis in calves may be similar to that of standard tube cystotomy. Additionally, it is cost effective, quick, field applicable procedure that minimizes exposure of abdominal cavity of metabolically compromised animals and requires minimum number of instruments. However, the technique needs to be tested in larger number of such calves using a better quality catheter of larger diameter before recommending its extensive use.

\section{References}

1. Ewoldt JM, Jones ML, Miesner MD. Surgery of obstructive urolithiasis in ruminants. Vet Clin North Am Food Anim Pract 2008;24:455-65.

2. Fazili MR. Cystic catheterization for obstructive urolithiasis in male calves: a study of 43 cases. Indian J Vet Surg 2002;23:112-3.

3. Hastings DH. Retention catheters for treatment of steers with ruptured bladders. J Am Vet Med Assoc 1965;147:1329-30.

4. Ewoldt JM, Anderson DE, Miesner MD, Saville W. Short- and long-term outcome and factors predicting survival after surgical tube cystotomy for treatment of obstructive urolithiasis in small ruminants. Vet Surg 2006;35:417-22.

5. Fortier LA, Gregg AJ, Erb HN, Fubini SL. Caprine obstructive urolithiasis: requirement for $2^{\text {nd }}$ surgical intervention and mortality after percutaneous tube cystotomy, or urinary bladder marsupialization. Vet Surg 2004;33:661-7.

6. Rakestraw PC, Fubini SL, Gilbert R0, Ward J0. Tube cystotomy for treatment of obstructive urolithiasis in small ruminants. Vet Surg 1995;24:498-505.

7. VanMetre DC, Fubini SL. Ovine and caprine urolithiasis: another piece of puzzle. Vet Surg 2006;35:413-16.

8. Haven ML. Comments on tube cystotomy in small ruminants. Vet Surg 1996;25:351-2.

9. Palmer JL, Dykes NL, Love K, Fubini SL. Contrast radiography of the lower urinary tract in the management of obstructive urolithiasis in small ruminants and swine. Vet Radiol Ultrasound 1998;39:175-80.

10. Streeter RN, Washburn KE, McCauley CT. Percutaneous tube cystotomy and vesicular irrigation for treatment of obstructive urolithiasis in a goat. J Am Vet Med Assoc 2002;221:567-649.

11. Rocken M, Stehle Ch, Mosel G, et al. Laparoscopic-assisted cystotomy for urolith removal in Geldings. Vet Surg 2006;35:394-7.

12. Fazili MR, Malik HU, Bhattacharyya HK, et al. Minimally invasive surgical tube cystotomy for treating obstructive urolithiasis in small ruminants with an intact urinary bladder. Vet Rec 2010;166:528-31.

13. Radostits OM, Gay CC, Blood DC, Hinchcliff KW. Veterinary medicine. A textbook of the diseases of cattle, sheep, pigs, goats and horses. 9th edn. China: Book Power with Saunders; 2003. pp 12-16.

14. Singh J, Singh K. Obstructive urolithiasis and uraemia in cattle and buffaloes-a review. Indian J Vet Surg 1990;11:1-20.

15. Bailey CB. Silica metabolism and silica urolithiasis in ruminants: a review. Canadian J Anim Sci 1981;61:219-35.

16. Bhatt GA, Ahmad SA, Prasad B. Studies on incidence and physiological chemistry of urinary calculi in bovines. Indian Vet $\mathrm{J}$ 1973;70:459-64.

17. Frank FW, Meinershagen WA, Baron RR, et al. Urolithiasis 1 Incidence of bladder calculi, urine properties and urethral diameters of feed lot steers. Am J Vet Res 1961; 22:899-901.

18. Buchoo BA, Sudan NA. Successful repair of ruptured urinary bladder in male calves - case report. Indian Vet J 1994;71:593-5.

19. Hussain SS, Moulvi BA. Treatment of ruptured bladder in a male calf: a case report. Indian Vet J 1986;63:948-51.

20. Gasthuys F, Steenhaut M, De Moor A, Sercu K. Surgical treatment of urethral obstruction due to urolithiasis in male cattle: a review of 85 cases. Vet Rec 1993;133: 522-6.

21. Fazili MR, Ansari MM. Prevalence of bovine obstructive urolithiasis in Kashmir valley. Indian Vet J 2007;84:540-1.

22. Hall LW, Clarke KW. Veterinary Anaesthesia, 9th edn. London: ELBS with Bailliere Tindall; 1991. pp 61-238.

23. Gera KL, Nigam JM. An experimental study on the effect of urethral ligation in calves (Bubalus bubalis). Indian Vet J 1980;57: 288-95.

24. Prasad B, Sharma SN, Singh J, Kohli RN. Surgical repair and management of bladder rupture in bullocks. Indian Vet J 1978; 55:905-11.

25. Sharma SN, Singh J, Ram Kumar V, et al. Acid-base status and blood gas alterations following experimental uremia in cattle. Am J Vet Res 1981;42:333-5. 